\title{
Insights into polyaromatic hydrocarbon biodegradation by Pseudomonas stutzeri CECT 930: operation at bioreactor scale and metabolic pathways
}

\author{
F. Moscoso $~ F$. J. Deive $\cdot$ M. A. Longo • \\ M. A. Sanromán
}

Received: 11 February 2013/Revised: 22 November 2013/ Accepted: 3 January 2014/Published online: 30 January 2014

(C) Islamic Azad University (IAU) 2014

\begin{abstract}
Contamination of the environment with polycyclic aromatic hydrocarbons is one of the major problems facing the industrialized nations today. In this work, Pseudomonas stutzeri CET 930 was studied for the first time as bioremediation agent for the degradation of effluents containing phenanthrene, pyrene and benzanthracene, both individually and mixed. The promising results of degradation obtained at flask scale $(92,63$ and $94 \%$ in 7 days, respectively) marks the onset of the operation at bench scale bioreactor. The overall biotransformation of phenanthrene, pyrene and benzanthracene in batch operation mode was 95,78 and $82 \%$ when present individually, and 100, 98 and $100 \%$ when carrying out the biological process in cometabolic conditions, respectively. We have demonstrated the great versatility of this strain for the degradation of structurally different contaminants, such as metal working fluids, polycyclic aromatic hydrocarbons or insecticides such as chlorpyrifos, which makes it a suitable candidate to be applied at industrial scale. In all cases, the experimental data were successfully fitted to models, which turned out to be valuable tools to classify the metabolites involved in the biodegradation process as biomass-related. Since a complete mineralization was pursued, the metabolic pathways of the studied contaminants have been proposed based on gas chromatography-mass spectrometry data.
\end{abstract}

Keywords Bioremediation - Pseudomonas stutzeri . Polyaromatic hydrocarbons · Bioreactor · Metabolic pathway

F. Moscoso · F. J. Deive $(\bowtie) \cdot$ M. A. Longo · M. A. Sanromán Department of Chemical Engineering, University of Vigo, Isaac Newton Building, 36310 Vigo, Spain e-mail: deive@uvigo.es

\section{Introduction}

Polycyclic aromatic hydrocarbons (PAHs) are common environmental pollutants that contain at least two or more fused aromatic rings in linear, angular or cluster arrangements. They represent a large and heterogeneous group of hydrophobic organic pollutants, and their presence in the environment is caused by natural and anthropogenic events, such as forest and rangeland fires or the incomplete combustion of fossil fuels and petroleum (Haritash and Kaushik 2009).

Among the major pollutants, PAHs are widely distributed environmental contaminants that are known to exert acutely toxic effects and/or possess mutagenic, teratogenic or carcinogenic properties (Simarro et al. 2011). Due to all these reasons, the US Environmental Protection Agency (USEPA) and the Agency for Toxic Substances and Disease Registry have proposed some of them as apriority pollutants (Moscoso et al. 2012d).

Although PAHs may be removed by physical (volatilization, photolysis and adsorption), chemical (chemical oxidation, photocatalysis) or biological (biosorption or biodegradation) techniques, the latter are considered a major route for their complete degradation. Microbial activities allow the mineralization of this kind of compounds into carbon dioxide and water. The potentiality of microbes as degradation agents of several PAHs thus points to biological treatment as the major promising alternative to attenuate the environmental impact caused by PAHs (Janbandhu and Fulekar 2011). Usually, there are many factors that influence the outcome of a biodegradation process. However, the microbial agent, the chemical structure of the pollutant and the environmental conditions are the most outstanding ones ( $\mathrm{Li}$ et al. 2008). Biodegradation pathways involve breakdown of organic 
compounds, being ring fission by intracellular oxidation and hydroxylation the typical initial steps.

The efficiency of PAH biodegradation under natural conditions is limited by their poor bioavailability, as a consequence of their low aqueous solubility and high hydrophobicity, which together with their high adsorption coefficient and high thermodynamic stability make up inherent features of this kind of pollutants (Cao et al. 2009). Bearing in mind these properties, considerable efforts have been focused on the enhanced solubility of these compounds with the addition of surfactants, amphiphilic molecules that increase the solubility of hydrophobic compounds by decreasing the interfacial surface tension at the aqueous/organic interphase. In this way, Sponza and Gok (2010) reported that surfactants have been shown to enhance both biodegradation and reaction rate, and Bautista et al. (2009) have even confirmed that Tween 80, a non-ionic surfactant, was used as carbon source by a Pseudomonas strain, thus being considered biodegradable (Álvarez et al. Álvarez et al. 2012a, b; Ulloa et al. 2012a, b).

During the last years, a wide phylogenetic diversity of bacteria belonging to genus Arthrobacter (Guo et al. 2008), Burkholderia (Kim et al. 2003), Pseudomonas (Chávez et al. 2004), Rhodococcus (Dean-Ross et al. 2002) and Sphingomonas (Madueno et al. 2011), among others, have been reported to be able to degrade PAHs. More specifically, bacteria from the genus Pseudomonas, which is present in a large number of different natural and contaminated environments, have been the subject of a great scientific interest due to both their high degree of physiological and genetic adaptability and their efficient capacity to aerobically degrade a wide range of aromatic compounds. From previous results of our group and information coming from the literature, Pseudomonas stutzeri strains have been demonstrated to be a promising microbial agent able to metabolize compounds such as PHE and PYR (Moscoso et al. 2012a; Seo et al. 2009; Kazunga and Aitken 2000). However, this is the first time that P. stutzeri is proposed for benzo[a]anthracene (BaA) degradation.

Frequently, contaminated sites and effluents are characterized by the occurrence of complex mixtures of several pollutants which is translated into an increased complexity of the biodegradation process. Since PAHs make up a group of persistent compounds, different strategies have been tackled to succeed in their biodegradation, such as cometabolism (Pathak et al. 2008; Klankeo et al. 2009).

In this work, PHE (a three aromatic ring molecule), PYR and $\mathrm{BaA}$ (both with four aromatic rings) have been used as models of low molecular weight (LWM) and high molecular weight (HWM) hydrocarbons to propose a viable biodegradation strategy. After assessing the biodegradability of an effluent containing each contaminant separately, the process was approached with a mixture of the three compounds. The bioremediation strategy was scaled-up from shake flasks to stirred tank bioreactor. Up to our knowledge, this is the first time that the bacterial strain $P$. stutzeri was used for proposing a viable degradation treatment of BaA, individually and mixed with other PAHs. This research work was conducted in the University of Vigo and was completed in October 2012.

\section{Materials and methods}

\section{Microorganism}

The bacterial strain $P$. stutzeri CECT 930, used in this study was obtained from the Spanish Type Culture Collection (ATCC 17588). P. stutzeri was inoculated in plates containing PS medium. The composition of this medium is (per litre)as following: yeast extract $2 \mathrm{~g}$, meat extract $1 \mathrm{~g}$, casein peptone $5 \mathrm{~g}, \mathrm{NaCl} 5 \mathrm{~g}$ and agar $15 \mathrm{~g}(\mathrm{pH}$ 7.2). The plates were incubated at $26^{\circ} \mathrm{C}$ for 5 days. $P$. stutzeri is a gram-negative, rod-shaped and single-polar flagellated bacterium (Lalucat et al. 2006).

\section{Chemicals and culture media}

Phenanthrene (PHE), pyrene (PYR) and benzo[a]anthracene (BaA) (purity higher than $99 \%$ ) used in degradation experiments were purchased from Sigma-Aldrich (Germany). Relevant properties of these compounds are shown in Table 1. The non-ionic surfactant Tween 80 was supplied by Merck. All chemicals used were at least reagent grade or better. PAHs stock solutions were $5 \mathrm{mM}$ in acetone.

Minimal medium (MM) was used for biodegradation experiment. The medium composition was as follows (per litre): $\mathrm{Na}_{2} \mathrm{HPO}_{4} \cdot 2 \mathrm{H}_{2} \mathrm{O} 8.5 \mathrm{~g}, \mathrm{KH}_{2} \mathrm{PO}_{4} 3.0 \mathrm{~g}, \mathrm{NaCl} 0.5 \mathrm{~g}$, $\mathrm{NH}_{4} \mathrm{Cl} 1.0 \mathrm{~g}, \mathrm{MgSO}_{4} \cdot 7 \mathrm{H}_{2} \mathrm{O} 0.5 \mathrm{~g}$ and $\mathrm{CaCl}_{2} 14.7 \mathrm{mg}$. MM also contained trace elements (per litre) that are as follows: $\mathrm{CuSO}_{4} \quad 0.4 \mathrm{mg}, \quad \mathrm{KI} \quad 1.0 \mathrm{mg}, \quad \mathrm{MnSO}_{4} \cdot \mathrm{H}_{2} \mathrm{O} \quad 4.0 \mathrm{mg}$, $\mathrm{ZnSO}_{4} \cdot 7 \mathrm{H}_{2} \mathrm{O} \quad 4.0 \mathrm{mg}, \mathrm{H}_{3} \mathrm{BO}_{3} 5.0 \mathrm{mg}, \mathrm{H}_{2} \mathrm{MoO}_{4} \cdot 2 \mathrm{H}_{2} \mathrm{O}$ $1.6 \mathrm{mg}$ and $\mathrm{FeCl}_{3} \cdot 6 \mathrm{H}_{2} \mathrm{O} 2.0 \mathrm{mg}$. A concentrated stock solution containing these salts was prepared and added to the medium $(2 \mathrm{~mL} / \mathrm{L})$.

Biodegradation cultures

Flask scale

Biodegradation experiments were carried out in $250-\mathrm{mL}$ Erlenmeyer flasks with $50 \mathrm{~mL}$ of MM, containing $1 \% \mathrm{w} / \mathrm{v}$ of surfactant Tween 80 and $2 \% \mathrm{v} / \mathrm{v}$ of a stock solution, in order to achieve the solubilization of the PAHs (up to 
Table 1 Main physical properties of used PAHs

\begin{tabular}{|c|c|c|c|c|c|c|c|}
\hline Compound & M.F. & Structure & M.W. & B.Pt. $\left({ }^{\circ} \mathrm{C}\right)$ & M.Pt. $\left({ }^{\circ} \mathrm{C}\right)$ & V.P. $\left(\mathrm{Pa}\right.$ at $\left.25^{\circ} \mathrm{C}\right)$ & $\begin{array}{l}\text { Aqueous } \\
\text { solubility }(\mathrm{mg} / \mathrm{L})\end{array}$ \\
\hline PHE & $\mathrm{C}_{14} \mathrm{H}_{10}$ & & 178.23 & 340 & 105.5 & $6.8 \times 10^{-4}$ & 1.20 \\
\hline PYR & $\mathrm{C}_{16} \mathrm{H}_{10}$ & & 202.26 & 393 & 156 & $2.5 \times 10^{-6}$ & 0.077 \\
\hline $\mathrm{BaA}$ & $\mathrm{C}_{18} \mathrm{H}_{12}$ & & 228.29 & 400 & 162 & $2.2 \times 10^{-8}$ & 0.010 \\
\hline
\end{tabular}

$100 \mu \mathrm{M})$. The non-ionic surfactant Tween 80 was chosen since non-ionic surfactants are less toxic to bacteria than anionic and cationic surfactants (Sartoros et al. 2005). Each flask, capped with cellulose stoppers, was inoculated (3\%) with actively growing cells in exponential phase $(24 \mathrm{~h})$. Cultures were incubated in the darkness for 7 days in an orbital shaker at $37^{\circ} \mathrm{C}$, initial pH 8.0 and $150 \mathrm{rpm}$. Samples were withdrawn at different times to monitor $\mathrm{PAH}$ biodegradation and cell density. All experiments were carried out in triplicate and the values shown in figures correspond to mean values with a standard deviation lower than $15 \%$.

\section{Bioreactor scale}

For the scaling up of the process, a stirred tank bioreactor (Biostat B, Braun, Germany) similar to that reported previously by our group was used (Moscoso et al. 2012a). It was filled with the medium described above containing $100 \mu \mathrm{M}$ of each individual PAH as well as with a mixture of them (each one at $100 \mu \mathrm{M}$ ). Temperature was maintained at $37{ }^{\circ} \mathrm{C}$ by circulation of thermostatted water, and the initial $\mathrm{pH}$ was adjusted to 8 . Bioreactor was inoculated with actively growing cells from 24-h flask cultures (3\% v/v). Air was supplied continuously at 0.17 vvm, and samples were taken regularly during the experimental period.

Analytical methods

\section{Cell growth determination}

Biomass concentration was measured by turbidimetry at $600 \mathrm{~nm}$, and the obtained values were converted to grams of cell dry weight per litre using an experimental calibration curve.

\section{PAHs analysis}

PHE, PYR and BaA concentrations in the culture media were analysed by reversed-phase high-performance liquid chromatography (HPLC) equipped with a reversed-phase C8 column $(150 \times 4.6 \mathrm{~mm}, 5 \mu \mathrm{m}$-particle-size, Zorbax Eclipse) with its corresponding guard column. The HPLC system was an Agilent 1100 equipped with a quaternary pump and photodiode array UV/Vis detector $(252.4 \mathrm{~nm})$. Five microliters of filtered cultivation media (through a $0.45-\mu \mathrm{m}$ Teflon filter) were injected and then eluted from the column at a flow rate of $1 \mathrm{~mL} \mathrm{~min}{ }^{-1}$ using acetonitrile/ water $(67: 33)$ as a mobile phase.

In order to identify intermediate compounds formed during the degradation process, aliquots of $5 \mathrm{~mL}$ were extracted twice with $5 \mathrm{~mL}$ of chloroform. The organic phase extractions were combined and dried over with anhydrous sodium sulphate (Zhao et al. 2009). one microliters of this organic phase was analysed using an Agilent GC 6850 gas chromatograph equipped with a HP5 MS capillary column $(30 \mathrm{~m} \times 250 \mu \mathrm{m}$ film thickness $\times 0.25 \mathrm{~mm}$, Agilent), operating with hydrogen as carrier gas, coupled to an Agilent MD 5975 mass spectrometer (MS). The GC injector was operated in splitless mode, and $1 \mu \mathrm{L}$ aliquots were injected using an autosampler; GC oven was programmed to hold $50{ }^{\circ} \mathrm{C}$ for $4 \mathrm{~min}$, then raise the temperature by $10{ }^{\circ} \mathrm{C} / \mathrm{min}$ to $270{ }^{\circ} \mathrm{C}$, which was held for $10 \mathrm{~min}$. PAH degradation products were identified by comparison with the NISTS search 2.0 database of spectra. 


\section{Results and discussion}

Growth and biodegradation of PAHs in cultures at flask scale

First of all, the efficiency of $P$. stutzeri for the degradation of PHE, PYR and BaA, both individually and mixed, was ascertained at small scale. As reported by Lalucat et al. (2006), this species of bacterium can grow diazotrophically, and in minimal salt medium with ammonium ions or nitrate and a single organic molecule, such as PHE, PYR and $\mathrm{BaA}$, as the sole carbon and energy source.

A variety of microbial growth and biodegradation kinetic models have been developed, proposed and used by many researchers. Such models allow the calculation of the time required to reduce a contaminant to a certain concentration, the estimation of how long it will take before a selected concentration will be attained and to predict the amount of biomass production achievable at a given time.

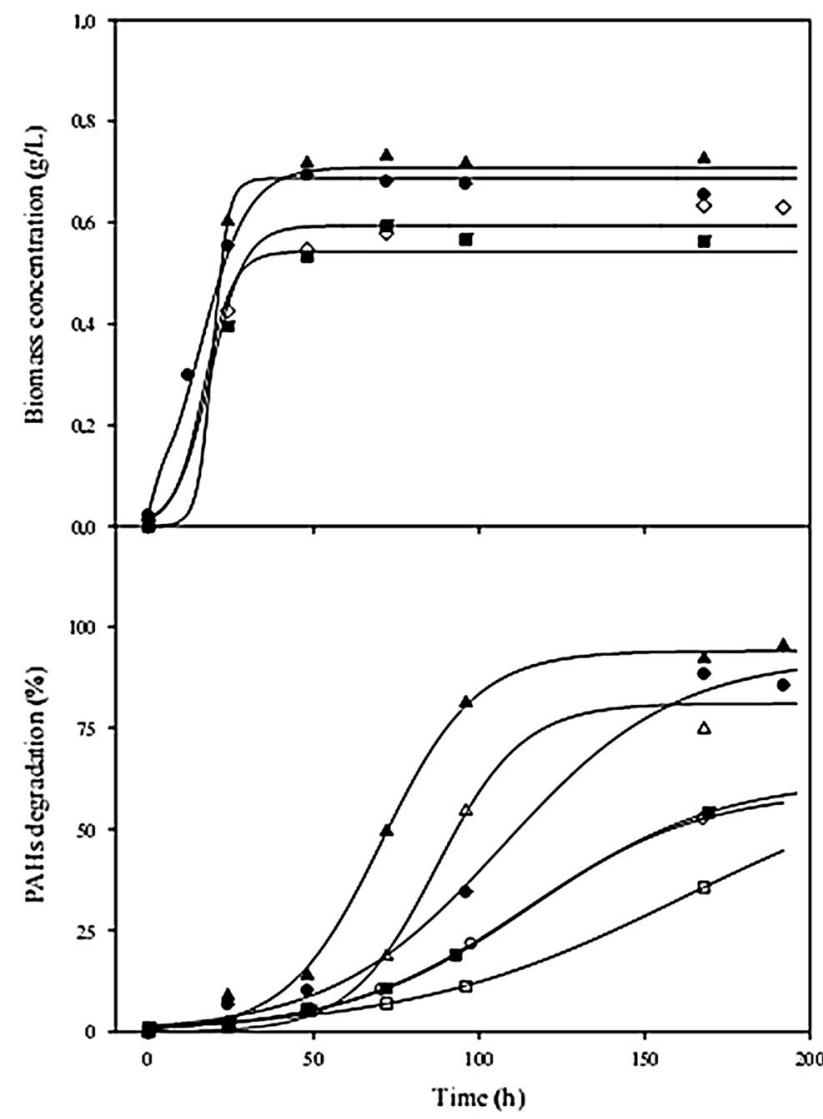

Fig. 1 Biomass concentration and PAHs degradation profiles in flask cultures of $P$. stutzeri in $\mathrm{MM}$ at $150 \mathrm{rpm}$ and $37^{\circ} \mathrm{C}$ : (circle) PHE; (square) PYR, (triangle) $\mathrm{BaA}$, (open diamond) $\mathrm{PHE}+\mathrm{PYR}+$ $\mathrm{BaA}$ for biomass concentration, PAHs degradation profiles individually (full symbols) and mixed (void symbols). Experimental data are represented by symbols and logistic model by solid lines. PHE data correspond to those reported by Moscoso et al. (2012a)
In this particular case, all experimental data were fitted to a logistic model (1), where $A$ is the biomass $(X, \mathrm{~g} / \mathrm{L})$ or the degradation rate $(D, \%)$ at a specific moment of the culture time $t(\mathrm{~h}), A_{0}$ and $A_{\max }$ are the initial and maximum biomass $\left(X_{0}\right.$ and $\left.X_{\max }, \mathrm{g} / \mathrm{L}\right)$ or the initial and maximum degradation rate $\left(D_{0}\right.$ and $\left.D_{\max }, \%\right)$ and $b$ is the maximum specific growth rate $\left(\mu, \mathrm{h}^{-1}\right)$ or the maximum specific degradation rate $\left(\mu_{\mathrm{D}}, \mathrm{h}^{-1}\right)$.

$A=\frac{A_{\max }}{1+\mathrm{e}^{\left[\operatorname{Ln}\left(\frac{A_{\max }}{A_{0}}-1\right)-b t\right]}}$

From the data depicted in Fig. 1, and the values of the parameters presented in Table 2, it is clear that the logistic model adequately fits to the experimental data $\left(R^{2}>0.96\right.$ in all cases). All the experimental data were fitted to these equations by using the SOLVER function in Microsoft EXCEL.

The analysis of the biomass parameters, listed in Table 2, allows one concluding the existence of quite higher levels of maximum biomass, similar to those reported by our group recently (Moscoso et al. 2012a) for the degradation of PHE at flask scale. In relation to the growth rate, the levels are much higher than those reported by Obayori et al. (2008) when they studied PYR biodegradation by a Pseudomonas species isolated from polluted tropical soils $\left(0.024 \mathrm{~h}^{-1}\right)$. It is noticeable that the introduction of a mixture of the three PAHs leads to a decrease both in the maximum biomass levels and growth rate.

With regard to the degradation parameters (Fig. 1b; Table 2), it seems clear that quite different maximum levels are reached depending on the PAH used. Thus, while the overall biotransformation of PYR was only $63 \%$ in 7 days, the levels corresponding to $\mathrm{BaA}$ and $\mathrm{PHE}$ reached about 94 and $92 \%$, respectively. This behaviour can be explained in terms of the different structure of PYR, which contrarily to the linear $\mathrm{PHE}$ and $\mathrm{BaA}$, it is a pericondensed molecule, which stands for a higher difficulty to be accessed and consequently to be transformed. Despite the lower values, it should be remarked that the results obtained are promising since they entail a quantitative amelioration in the times required to reach the maximum, when compared with the data reported by Obayori et al. (2008) (30 days incubation period to reach similar levels of biodegradation).

Also, the introduction of a mixture containing PHE, PYR and BaA entails a reduction in the maximum levels of biodegradation of all the contaminants, as could be envisaged from the analysis of the biomass parameters. Sartoros et al. (2005) studied cometabolism of Anthracene (ANTtricyclic aromatic hydrocarbon, similar to PHE but with a linear structure) and PYR in order to show the ability of the microbes to degrade hydrocarbons individually, indicating 
Table 2 Growth and PAH biodegradation kinetic parameters defining the logistic and Luedeking and Piret-type models in cultures of $P$. stutzeri at flask and bioreactor scale

\begin{tabular}{|c|c|c|c|c|c|c|c|c|c|c|c|c|c|}
\hline \multicolumn{2}{|c|}{ Experiment } & \multicolumn{4}{|c|}{ Biomass parameters } & \multicolumn{4}{|c|}{ PAHs degradation parameters } & \multicolumn{4}{|c|}{ Luedeking and Piret parameters } \\
\hline PAHs & Scale & $X_{0}(\mathrm{~g} / \mathrm{L})$ & $X_{\max }(\mathrm{g} / \mathrm{L})$ & $\mu\left(\mathrm{h}^{-1}\right)$ & $R^{2}$ & $\begin{array}{l}D_{0} \\
(\% \text { deg })\end{array}$ & $\begin{array}{l}D_{\max } \\
(\% \text { deg })\end{array}$ & $\begin{array}{l}\mu_{\mathrm{D}} \\
\left(\mathrm{h}^{-1}\right)\end{array}$ & $R^{2}$ & $D_{0}(\% \operatorname{deg})$ & $\begin{array}{l}m(\% \text { deg } \\
\mathrm{L} / \mathrm{g})\end{array}$ & $\begin{array}{l}n(\% \text { deg } \\
\mathrm{L} / \mathrm{g} / \mathrm{h})\end{array}$ & $R^{2}$ \\
\hline $\mathrm{PHE}^{\mathrm{a}}$ & Flask & 0.073 & 0.708 & 0.138 & 0.99 & 1.487 & 92.351 & 0.038 & 0.99 & 1.22 & 9.41 & 0.77 & 0.98 \\
\hline PYR & & 0.013 & 0.543 & 0.223 & 0.97 & 0.993 & 62.357 & 0.035 & 0.99 & 2.367 & 15.311 & 0.761 & 0.99 \\
\hline $\mathrm{BaA}$ & & 0.001 & 0.687 & 0.433 & 0.96 & 0.661 & 93.990 & 0.070 & 0.99 & 0 & 15.899 & 0.903 & 0.90 \\
\hline PHE-Mx & & 0.016 & 0.594 & 0.191 & 0.98 & 0.960 & 59.810 & 0.036 & 0.99 & 2.005 & 14.709 & 0.647 & 0.88 \\
\hline PYR-Mx & & & & & & 1.367 & 56.547 & 0.024 & 0.99 & 0.636 & 7.874 & 0.420 & 0.99 \\
\hline $\mathrm{BaA}-\mathrm{Mx}$ & & & & & & 0.101 & 81.044 & 0.077 & 0.99 & 0.321 & 10.676 & 0.966 & 0.83 \\
\hline $\mathrm{PHE}^{\mathrm{a}}$ & Reactor & 0.010 & 0.557 & 0.183 & 0.97 & 1.0 & 94.729 & 0.186 & 0.98 & 3.97 & 121.21 & 0.47 & 0.98 \\
\hline PYR & & 0.084 & 0.587 & 0.101 & 0.92 & 6.657 & 78.285 & 0.019 & 0.99 & 3.118 & 11.067 & 0.519 & 0.98 \\
\hline $\mathrm{BaA}$ & & 0.049 & 0.635 & 0.193 & 0.99 & 5.000 & 81.297 & 0.045 & 0.98 & 0 & 29.271 & 0.672 & 0.99 \\
\hline PHE-Mx & & 0.058 & 0.497 & 0.079 & 0.96 & 6.504 & 100.000 & 0.035 & 0.99 & 0.931 & 75.882 & 0.284 & 0.90 \\
\hline PYR-Mx & & & & & & 5.940 & 98.467 & 0.032 & 0.99 & 0.856 & 56.375 & 0.495 & 0.95 \\
\hline $\mathrm{BaA}-\mathrm{Mx}$ & & & & & & 5.809 & 100.000 & 0.035 & 0.99 & 1.187 & 61.418 & 0.502 & 0.96 \\
\hline
\end{tabular}

${ }^{a}$ Data reported by Moscoso et al. (2012a)

that the degradation of these two PAHs was not dependent on cometabolism (in 12 days, $100 \%$ of PYR was transformed while ANT degradation was $80 \%$ ). According to these results, some authors suggested that the simultaneous bacteria-mediated $\mathrm{PAH}$ biodegradation was strongly influenced by their different bioavailabilities (González et al. 2011; Silva et al. 2009; Peng et al. 2009).

It should be highlighted that, despite the existing reduction in the maximum degradation yields attained, the values are still very promising, since a minimum of $60 \%$ is obtained after just 1 week of treatment.

One approach to characterize substrate biodegradation, in order to define a set of factors or variables affecting the kinetics of biodegradation and identifying an appropriate kinetic model correlating specific growth rate and PAHs removal, can be obtained by applying the model reported by Marqués et al. (1986) and exhaustively explained in previous works of the group (Deive et al. 2010).

$$
\begin{aligned}
D= & D_{0}+m X_{0}\left\{\frac{e^{\mu t}}{\left[1-\left(\frac{X_{0}}{X_{\max }}\right)\left(1-\mathrm{e}^{\mu t}\right)\right]}-1\right\} \\
& +n\left(\frac{X_{\max }}{\mu}\right) \ln \left[1-\left(\frac{X_{0}}{X_{\max }}\right)\left(1-\mathrm{e}^{\mu t}\right)\right]
\end{aligned}
$$

This equation allows defining biodegradation as a function of a "growth-associated" parameter $(m)$, or/and a "nongrowth-associated" parameter $(n)$. The values obtained are presented in Table 2. It becomes patent that the biodegradation process is more dependent on the biomass production, since in all cases, $m$ is, at least, more than nine times higher than $n$.
Growth and biodegradation cultures at bench scale bioreactor

After having checked the viability of the biodegradation of the selected PAHs mixture at flask scale, the study was approached at bioreactor scale. The biodegradation experiments in a 5-L bioreactor were operated in batch mode to study the scale up effect from $250-\mathrm{mL}$ shake flasks. The batch was initially run for single substrate degradation study with a PAH concentration of $100 \mu \mathrm{M}$, to finally introduce a mixture of the three selected PAHs at $100 \mu \mathrm{M}$ each, following the same strategy used at flask scale. The bioreactor used was fitted with a Rushton turbine driven by a DC motor, in order to provide the culture with an increased mass transfer, which could ultimately allow enhancing the bioavailability of the contaminants.

Therefore, the results of cellular concentration and biodegradation obtained after carrying out the biological reactions are shown in Fig. 2, and the kinetic parameters defining the microbiological process are also listed in Table 2. It can be checked that the levels of biodegradation reached are higher (PHE $95 \%$, PYR 78 and BaA 81\%) than those obtained at flask scale, thus confirming our preliminary hypothesis of a possible higher bioavailability of the pollutant. In general, these levels are higher than those reported in the literature. For instance, Trably and Patureau (2006) worked in a continuous bioreactor at an hydraulic retention time of 20 days, to achieve about $90 \%$ of PHE biodegradation, while Nasseri et al. (2010) needed 3 weeks to reach $87 \%$ of remediation in Pseudomonas cultures carried out in a slurry phase bioreactor. In the 


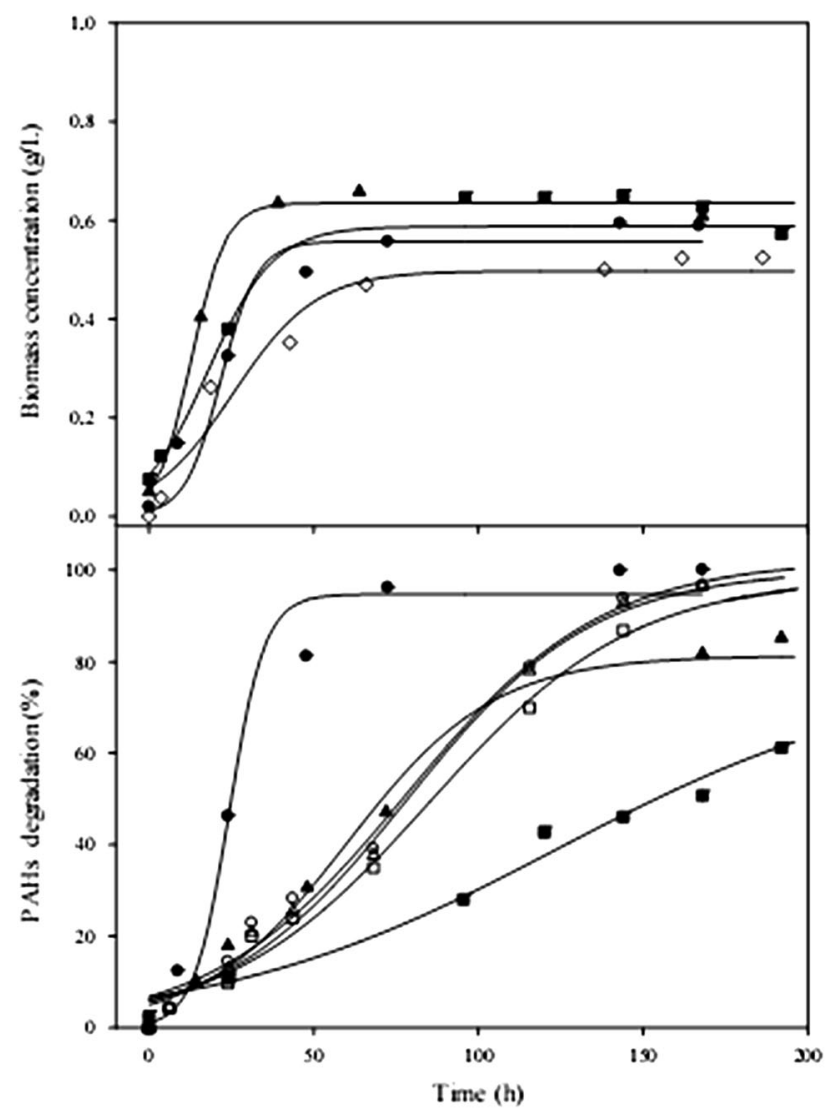

Fig. 2 Biomass concentration (a) and PAH degradation profiles (b) in bioreactor cultures of $P$. stutzeri in $\mathrm{MM}$ at $300 \mathrm{rpm}, 0.17 \mathrm{vvm}$ and $37^{\circ} \mathrm{C}$ : (filled circle) PHE; (filled square) PYR, (filled triangle) $\mathrm{BaA}$, (open diamond) PHE + PYR + BaA for biomass concentration, PAHs degradation profiles individually (full symbols) and mixed (void symbols). Experimental data are represented by symbols and logistic model by solid lines. PHE data correspond to those reported by Moscoso et al. (2012a)

same way, Ventaka et al. (2008) investigated the use of bio slurry phase reactors to degrade PYR at $120 \mathrm{~h}$ of HRT, reaching similar levels of degradation as those reported in this work.

On the other hand, a final experiment was performed to check the ability of the selected strain to biodegrade a mixture of all the contaminants. Since percentages of removal for the three contaminants are higher, reaching an almost complete degradation in all cases (100\% of PHE, $98 \%$ of PYR and $100 \%$ of BaA), we can conclude that the hydrodynamic setting existing inside the bioreactor furthers the cometabolic degradation of the three contaminants. The values obtained are also superior to those reported by Sponza and Gok (2010), who studied the removal of PAHs from petrochemical wastewater using an aerobic stirred tank bioreactor during 25 days (74\% PHE, $60 \%$ PYR and $37 \% \mathrm{BaA}$ ). Regarding the advantages of this paper in comparison with previous consortia obtained from contaminated soils, the first outstanding feature that should be stressed is that this microorganism is able to efficiently carry out the biological degradation without including the typical sterilization step, which is very advantageous in terms of time consumption and bioprocess economy. Besides, we have demonstrated that the operation with this axenic culture allows a tremendous versatility, since it is able to metabolize extremely recalcitrant compounds such as Metal Working Fluids, or hydrophobic pesticides such as chlorpyrifos, as we have demonstrated very recently. (Moscoso et al. 2012b, c, 2013). More specifically, this last paper has evidenced that the microbial consortium obtained from polluted soil was almost completely unable to biodegrade the insecticide chlorpyrifos, while the cultivation of $P$. stutzeri allowed reaching values around $80 \%$.

Silva et al. (2009) reported that PAH cometabolization could strongly alter the final results of biodegradation in a given remediation process, since the degradation of one type of PAH can affect the degradation of other PAH. In this way, in our case, a LMW PAH such as PHE may affect the degradation of a HMW PAH, such as PYR and BaA, and vice versa, via cometabolism, induction of enzyme activities by related degradation intermediates or via competitive inhibition or toxicity (Dean-Ross et al. 2002). The metabolic cooperation by several microorganisms may result in enhanced PAH utilization, since metabolic intermediates produced by some organisms may serve as substrate for the growth of others and further studies taking into account a microbial consortium should not be discarded.

Finally, the analysis of the Luedeking and Piret parameters allow confirming the same behaviour found at flask scale, with a stronger dependence of degradation on the biomass parameter $m$ (50 times higher than $n$ in some cases). This behaviour is coincident with what was found in other biological processes devoted to the degradation of dyes or to the production of metabolites (Deive et al. 2009, 2010).

Identification of metabolic pathway of PAHs

It is well known that PAHs can be biodegraded by several groups of microorganisms. Among them, P. stutzeri stands out as an ubiquitous bacterium with a high degree of physiological and genetic adaptability (Lalucat et al. 2006). Therefore, the last step of this work consisted of elucidating the metabolic pathways followed to degrade this kind of compounds. Proven the low levels of biomass adsorption (maximum levels around $15 \%$ ), a biotransformation of the contaminants is foreseen. Usually, aerobic catabolism of PAHs involves a wide variety of peripheral degradation pathways that transform substrates into a small number of common intermediates that can be further processed by a new central pathway to tricarboxylic acid 
(TCA) cycle intermediates (Peng et al. 2009; Mrozik 2003; Cerniglia 1993; Cerniglia et al. 1994).

It has long been known that the initial step in the aerobic catabolism of a PAH molecule by bacteria occurs via oxidation of the PAH to a dihydrodiol by a multicomponent enzyme system (Zhong et al. 2011). These dihydroxylated intermediates may then be processed through either an ortho cleavage type of pathway or a meta cleavage type of pathway, leading to central intermediates such as protocatechuates and catechols, which are further converted to tricarboxylic acid cycle intermediates (van der Meer et al. 1992). Hence, as reported by Cao et al. (2009), metabolites of naphthalene, such naphthalene dihydrodiols, are potentially more bioavailable and could be more toxic than naphthalene precursor, further demonstrating the importance of analysing the metabolic route for degrading the contaminants.

Previous results of our group (Moscoso et al. 2012a) allowed the elucidation of the metabolic degradation pathway of the LMW PHE. From the detection of two different products, we could demonstrate that it was degraded trough protocatechuate route instead of the salicylate one. These results will also serve to support the study of the metabolic routes followed to degrade the HMW PAHs, PYR and BaA.

Despite the increasing interest in PAH biodegradation, the metabolization of HMW PAHs is not as well understood yet. Thus, PYR, a pericondensed four ring PAH with a similar structure to several carcinogenic PAHs was often used as a model HMW PAHs for biodegradation (Zheng et al. 2007). Metabolites such as 1-hydroxy-2-naphthoic acid, phthalic acid and cinnamic acid (although their abundance is insignificant in relation to phatalic acid, which is the main compound in PHE degradation) were identified by GC-MS analyses. It can be concluded that after an initial dioxygenation steps, well described in the literature (Seo et al. 2009), PYR transforms into 3,4-dihydroxyphenanthrene, which is also an intermediate detected in PHE degradation. Therefore, it can be confirmed that PYR could be mineralized following PHE pathway, as described previously (Moscoso et al. 2012a, b, c). The schematic pathway proposed for the degradation of PYR by bacteria P. stutzeri is shown in Fig. 3 .

However, very little is known about the bacteria able to utilize PAHs such as benzo[a]pyrene and BaA. Actually, up to our knowledge, this is the first time that the pathway for the bacterial degradation of $\mathrm{BaA}$ is presented. The degradation route proposed for $\mathrm{BaA}$ is depicted in Fig. 4, and the main metabolites identified by GC-MS data are summarized in Table 3. As it could be envisaged, the initial steps include a dioxygenation with the consequent production of 3 different diols. Depending on the position, several pathways can be followed. Diols can be formed in

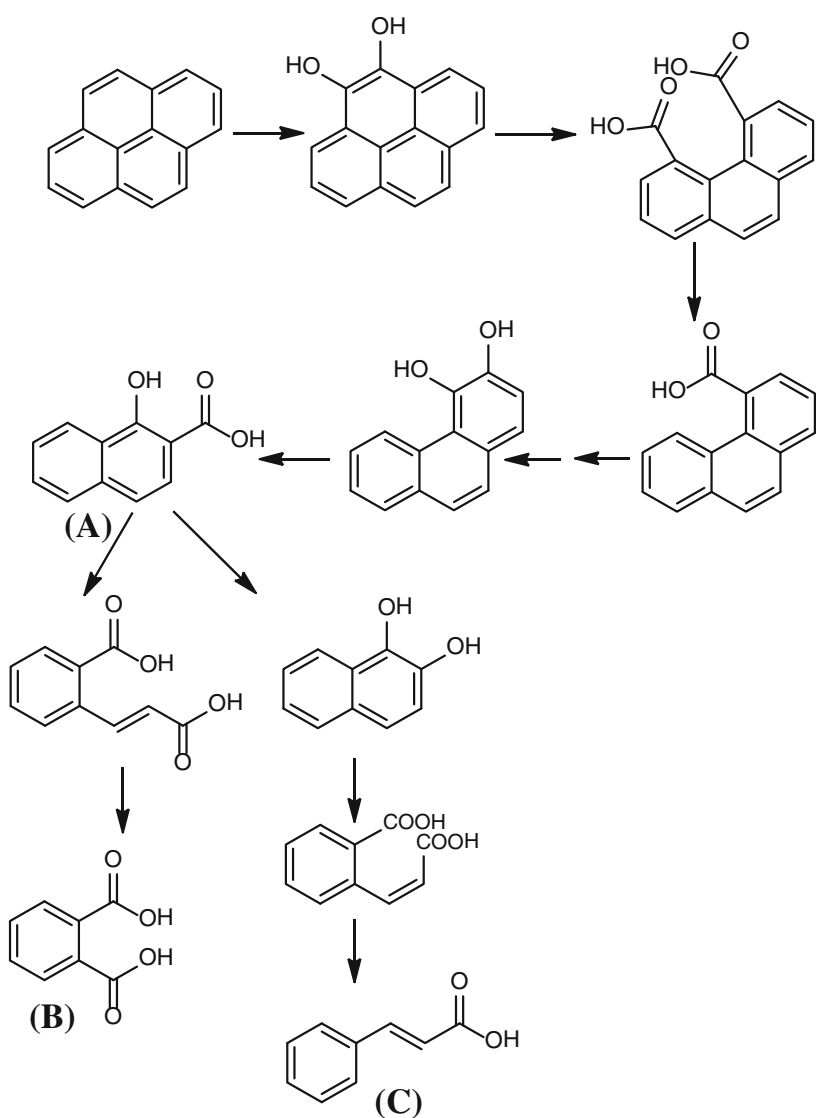

Fig. 3 Proposed metabolic pathway of PYR by P. stutzeri cultured at bioreactor scale. a 1-Hydroxy-2-naphthoic acid, b phthalic acid and c cinnamic acid

Table 3 Identification of metabolites produced during degradation of mixed PAHs (PHE + PYR + BaA) based on GCMS properties

\begin{tabular}{lcll}
\hline Peak & RT $(\mathrm{min})$ & $\mathrm{m} / \mathrm{z}$ of fragment ions & Structural suggestion \\
\hline 1 & 8.26 & $372.3(100), 373(27)$, & $\begin{array}{c}\text { 9-Octadecenoic acid } \\
\text { phenylmethylester }\end{array}$ \\
& & $374(4)$ & Terephthalate \\
2 & 15.15 & $149(100), 165(87)$, & \\
& & $65(42)$ & \\
3 & 15.98 & $149(100), 177(25)$ & Diethyl phthalate \\
4 & 18.46 & $154(100), 125(68)$ & Benzenemethanol \\
5 & 18.82 & $108(100), 78(73)$, & Benzenemethoxy \\
& & $95(73)$ & \\
6 & 20.03 & $180(100), 208(98)$, & $9,10-$ Anthracenedione \\
& & $152(78)$ & (anthraquinone) \\
7 & 24.95 & $149(100), 167(44)$, & Diisooctyphtaalate \\
& \multicolumn{3}{c}{$279(22)$} \\
\hline
\end{tabular}

position 8-9 or 10-11 (Fig. 4a, b). In this case, after a few steps, compounds such as 3,4-dihydroxyphenanthrene were detected by GC-MS. Metabolites such as phenanthrol, which is a target compound detected in the PHE pathway, 
Fig. 4 Proposed metabolic pathway of BaA by $P$. stutzeri cultured at bioreactor scale (a)

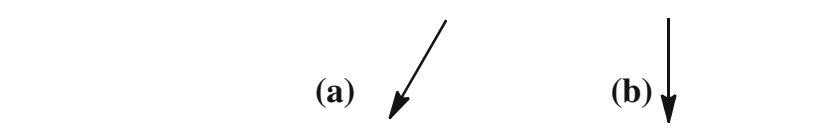<smiles>c1ccc2cc3c(ccc4ccccc43)cc2c1</smiles>

(c)<smiles>Oc1ccc2ccc3cc4ccccc4cc3c2c1O</smiles>

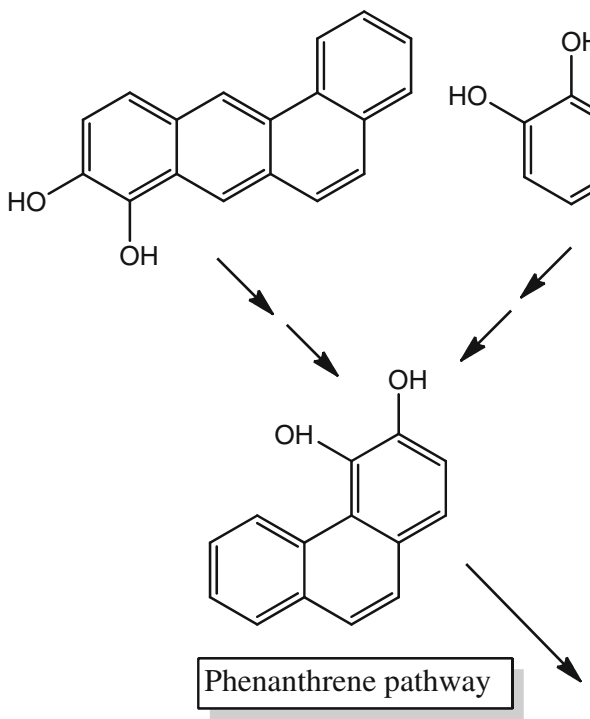

(b)<smiles>C=c1cc2c(ccc3ccccc32)cc1=CO</smiles><smiles>O=C1c2ccccc2C(=O)c2ccccc21</smiles>

Anthraquinone pathway

confirm these specific routes as possible pathways to degrade $\mathrm{BaA}$. On the other hand, metabolites such as anthraquinone, a typical metabolite formed during the degradation of the anthracene (and more common intermediate in fungus degradation) confirm the viability of the formation of 1-2 benzanthrazenediol (Fig. 4c), which can be transformed in anthracene and subsequently in anthraquinone. This compound was also detected by HPLC data, during the first stages of the degradation process.

\section{Conclusion}

Biodegradation of different PAHs involving 3-4 rings has been successfully performed by the selected bacterium, $P$. stutzeri. Different rates of growth and degradation were reached depending on the structure of each $\mathrm{PAH}$, scale used (flask vs. bioreactor) and also on the metabolic conditions. This study also confirmed the promising potential of the microorganism used to degrade mixed PAHs, given the excellent results of degradation in cometabolic conditions, which are the most probably found in real effluents. It should be noticed that this microorganism is able to efficiently carry out the biological degradation without including the typical sterilization step, which is very advantageous in terms of time consumption and bioprocess economy. Besides, we have demonstrated that the operation with this axenic culture allows a tremendous versatility, since it is able to metabolize extremely recalcitrant compounds such as metal working fluids or hydrophobic pesticides such as chlorpyrifos. The logistic and Luedeking and Piret-type models were suitably fitted to the experimental data which allowed a new insight into the kinetic characterization of the biodegradation process. Finally, GC-MS data served our goal to propose a possible pathway route to mineralize HMW PAHs such as PYR and BaA.

Acknowledgments This Project was funded by the Spanish Ministry of Science and Innovation (CTQ2008-03059/PPQ). The authors thank Xunta de Galicia for funding through a Isidro Parga Pondal contract. 


\section{References}

Álvarez MS, Moscoso F, Rodríguez A, Sanromán MA, Deive FJ (2012a) Triton $X$ surfactants to form aqueous biphasic systems: experimental and correlation. J Chem Thermodyn 54:385-392

Álvarez MS, Moscoso F, Deive FJ, Sanromán MA, Rodríguez A (2012b) On the phase behaviour of polyethoxylated sorbitan (Tween) surfactants in the presence of potassium inorganic salts. J Chem Thermodyn 55:151-158

Bautista LF, Sanz R, Molina MC, González N, Sánchez D (2009) Effect of different non-ionic surfactants on the biodegradation of PAHs by diverse aerobic bacteria. Int Biodeterior Biodegrad 63:913-922

Cao B, Nagarajan K, Loh KC (2009) Biodegradation of aromatic compounds: current status and opportunities for biomolecular approaches. Appl Microbiol Biotechnol 85:207-228

Cerniglia CE (1993) Biodegradation of polycyclic aromatic hydrocarbons. Curr Opin Biotechnol 4:331-338

Cerniglia CE, Gibson DT, Dodge RH (1994) Metabolism of benz[a]anthracene by the filamentous fungus Cunninghamella elegans. Appl Environ Microbiol 60:3931-3938

Chávez FP, Lunsdorf H, Jerez CA (2004) Growth of polychlorinatedbiphenyl-degrading bacteria in the presence of biphenyl and chlorobiphenyls generates oxidative stress and massive accumulation of inorganic polyphosphate. Appl Environ Microbiol 70:3064-3072

Dean-Ross D, Moody J, Cerniglia CE (2002) Utilization of mixtures of polycyclic aromatic hydrocarbons by bacteria isolated from contaminated sediment. FEMS Microbiol Ecol 41:1-7

Deive FJ, Carvalho E, Pastrana L, Rua ML, Longo MA, Sanromán MA (2009) Assessment of relevant factors influencing lipolytic enzyme production by Thermus thermophilus HB27 in laboratory-scale bioreactors. Chem Eng Technol 32:606-612

Deive FJ, Domínguez A, Barrio T, Moscoso F, Morán P, Longo MA, Sanromán MA (2010) Decolorization of dye Reactive Black 5 by newly isolated thermophilic microorganisms from geothermal sites in Galicia (Spain). J Hazard Mater 182:735-742

González N, Simarro R, Molina MC, Bautista LF, Delgado L, Villa JA (2011) Effect of surfactants on PAH biodegradation by a bacterial consortium and on the dynamics of the bacterial community during the process. Bioresour Technol 102:9438-9446

Guo W, Li D, Tao Y, Gao P, Hu J (2008) Isolation and description of a stable carbazole-degrading microbial consortium consisting of Chryseobacterium sp. NCY and Achromobacter sp. NCW. Curr Microbiol 57:251-257

Haritash AK, Kaushik CP (2009) Biodegradation aspects of polycyclic aromatic hydrocarbons (PAHs): a review. J Hazard Mater 169:1-15

Janbandhu A, Fulekar MH (2011) Biodegradation of phenanthrene using adapted microbial consortium isolated from petrochemical contaminated environment. J Hazard Mater 187:333-340

Kazunga C, Aitken MD (2000) Products from the incomplete metabolism of pyrene by polycyclic aromatic hydrocarbondegrading bacteria. Appl Environ Microbiol 66:1917-1922

Kim TJ, Lee EY, Kim YJ, Cho KS, Ryu HW (2003) Degradation of polyaromatic hydrocarbons by Burkholderia cepacia 2A-12. World J Microbiol Biotechnol 19:411-417

Klankeo P, Nopcharoenkul W, Pinyakong O (2009) Two novel pyrene-degrading Diaphorobacter sp. and Pseudoxanthomonas sp. isolated from soil. J Biosci Bioeng 108:488-495

Lalucat J, Bennasar A, Bosch R, García-Valdés E, Palleroni NJ (2006) Biology of Pseudomonas stutzeri. Microbiol Mol Biol Rev 70:510-547

Li X, Li P, Lin X, Zhang C, Li Q, Gong Z (2008) Biodegradation of aged polycyclic aromatic hydrocarbons (PAHs) by microbial consortia in soil and slurry phases. J Hazard Mater 150:21-26
Madueno L, Coppotelli BM, Álvarez HM, Morelli IS (2011) Isolation and characterization of indigenous soil bacteria for bioaugmentation of PAH contaminated soil of semiarid Patagonia, Argentina. Int Biodeterior Biodegrad 65:345-351

Marqués A, Estañol I, Alsina JM, Fusté C, Simon-Pujol D, Guinea J, Congregado F (1986) Production and rheological properties of the extracellular polysaccharide synthesized by Pseudomonas sp. strain EPS-5028. Appl Environ Microbiol 52:1221-1223

Moscoso F, Deive FJ, Longo MA, Sanromán MA (2012a) Technoeconomic assessment of phenanthrene degradation by Pseudomonas stutzeri CECT 930 in a batch bioreactor. Bioresour Technol 104:81-89

Moscoso F, Deive FJ, Villar P, Pena R, Herrero L, Longo MA, Sanromán MA (2012b) Assessment of a process to degrade metal working fluids using Pseudomonas stutzeri CECT 930 and indigenous microbial consortia. Chemosphere 86:420-426

Moscoso F, Deive FJ, Longo MA, Sanromán MA (2012c) Efficient PAHs biodegradation by a bacterial consortium at flask and bioreactor scale. Bioresour Technol 119:270-276

Moscoso F, Teijiz I, Sanromán MA, Deive FJ (2012d) On the suitability of a bacterial consortium to implement a continuous PAHs biodegradation process in a stirred tank bioreactor. Ind Eng Chem Res 51:15895-15900

Moscoso F, Teijiz I, Deive FJ, Sanromán MA (2013) Approaching chlorpyrifos bioelimination at bench scale bioreactor. Bioprocess Biosyst Eng. doi:10.1007/s00449-012-0876-0

Mrozik A (2003) Bacterial degradation and bioremediation of polycyclic aromatic hydrocarbons. Pol J Environ Stud 12:15-25

Nasseri S, Kalantary R, Nourieh N, Naddafi K, Mahvi A, Baradaran N (2010) Influence of bioaugmentation in biodegradation of PAHscontaminated soil in bioslurry phase reactor. Iran J Environ Health Sci Eng 7:199-208

Obayori OS, Ilori MO, Adebusoye SA, Oyetibo GO, Amund OO (2008) Pyrene-degradation potentials of Pseudomonas species isolated from polluted tropical soils. World J Microbiol Biotechnol 24:2639-2646

Pathak H, Jain P, Jaroli DP, Lowry M (2008) Degradation of phenanthrene and anthracene by Pseudomonas strain, isolated from coastal area. Bioremediat J 12:111-116

Peng RH, Xiong AS, Xue Y, Fu XY, Gao F, Zhao W, Tian YS, Yao QH (2009) Microbial biodegradation of polyaromatic hydrocarbons. FEMS Microbiol Rev 32:927-955

Sartoros C, Yerushalmi L, Béron P, Guiot SR (2005) Effects of surfactant and temperature on biotransformation kinetics of anthracene and pyrene. Chemosphere 61:1042-1050

Seo JS, Keum YS, Li QX (2009) Bacterial degradation of aromatic compounds. Int J Environ Res Public Health 6:278-309

Silva ÍS, Santos EC, Menezes CR, Faria AF, Franciscon E, Grossman M, Durrant LR (2009) Bioremediation of a polyaromatic hydrocarbon contaminated soil by native soil microbiota and bioaugmentation with isolated microbial consortia. Bioresour Technol 100:4669-4675

Simarro R, González N, Bautista LF, Sanz R, Molina MC (2011) Optimisation of key abiotic factors of PAH (naphthalene, phenanthrene and anthracene) biodegradation process by a bacterial consortium. Water Air Soil Pollut 217:365-374

Sponza DT, Gok O (2010) Effect of rhamnolipid on the aerobic removal of polyaromatic hydrocarbons (PAHs) and COD components from petrochemical wastewater. Bioresour Technol 101:914-924

Trably E, Patureau D (2006) Successful treatment of low PAHcontaminated sewage sludge in aerobic bioreactors. Environ Sci Pollut Res Int 13:170-176

Ulloa G, Coutens C, Sánchez M, Sineiro J, Rodríguez A, Deive FJ, Núñez MJ (2012a) Sodium salt effect on aqueous solutions 
containing Tween 20 and Triton X-102. J Chem Thermodyn 47:62-67

Ulloa G, Coutens C, Sánchez M, Sineiro J, Fábregas J, Deive FJ, Rodríguez A, Núñez MJ (2012b) On the double role of surfactants as microalga cell lysis agents and antioxidants extractants. Green Chem 14:1044-1051

van der Meer JR, de Vos WM, Harayama S, Zehnder AJB (1992) Molecular mechanisms of genetic adaptation to xenobiotic compounds. Microbiol Rev 56:677-694

Venkata MS, Prasanna D, Purushotham RB, Sarma PN (2008) Ex situ bioremediation of pyrene contaminated soil in bio-slurry phase reactor operated in periodic discontinuous batch mode: influence of bioaugmentation. Int Biodeterior Biodegrad 62:162-169
Zhao HP, Wu QS, Wang L, Zhao XT, Gao HW (2009) Degradation of phenanthrene by bacterial strain isolated from soil in oil refinery fields in Shanghai China. J Hazard Mater 164:863-869

Zheng XJ, Blais JF, Mercier G, Bergeron M, Drogui P (2007) PAH removal from spiked municipal wastewater sewage sludge using biological, chemical and electrochemical treatments. Chemosphere 68:1143-1152

Zhong Y, Luan T, Lin L, Liu H, Tam NFY (2011) Production of metabolites in the biodegradation of phenanthrene, fluoranthene and pyrene by the mixed culture of Mycobacterium sp. and Sphingomonas sp. Bioresour Technol 102:2965-2972 